\title{
Shame: The Emotional Basis of Library Anxiety
}

\section{Erin L. McAfee}

In 1986, Constance Mellon found that 75 to 85 percent of undergraduate students experienced library anxiety as well as shame about their anxiety. Fifteen years earlier, Helen Block Lewis began her groundbreaking research in shame theory. This paper explores the affective components of library anxiety using the pioneering research of Constance Mellon, Helen Block Lewis, and others. Two issues are discussed: 1) how unacknowledged, recursive shame or "shame about shame" creates painful, emotional states such as library anxiety; and 2) how to recognize and neutralize unacknowledged shame in library service interactions.

\section{Introduction}

Few other institutions make us reflect more on our intellectual identity than the academic library. Most everyone, regardless of education level, accomplishments, or status, wants to be regarded as intelligent and knowledgeable. The academic library embodies intellectual competency; and, for many students, just planning a trip to the library can cause anxiety. Self-conscious emotions are normal, and, in most unfamiliar environments, they will naturally diminish. Asking a clerk in a sports store a question about running shoes does not expose one's physical strength, but asking a research question in an academic library reveals much about a person's education level and research experience. As the American sociologist Charles Cooley explains, it is not the reflection of ourselves that we feel is important, "but the imagined effect of this reflection upon another's mind. This is evident from the fact that the character and weight of that other, in whose mind we see ourselves, makes all the difference with our feeling." ${ }^{1}$

\section{Problem Statement}

Important and much needed research has been developed since Constance Mellon presented her theory of library anxiety, but affective components remain unexamined and elusive. ${ }^{2}$ Emotions are difficult to measure in quantitative studies, and feelings that drive library anxiety are often too disguised for qualitative analysis. Library and information science (LIS) researchers have noted that, until the causes of library anxiety are fully understood, we can only strive to treat its symptoms. ${ }^{3}$ The purpose of this analysis is to identify the affective components that cause the painful, emotional state of library anxiety.

Erin L. McAfee, retired Senior User Services Associate, Fondren Library at Rice University; e-mail:erinm@ rice.edu. This paper is based on a presentation called "Acknowledging the Shame Affect in Library Anxiety" given at the Texas Library Association's 2015 District 8 Fall Conference, September 25, 2015. (C2018 Erin L. McAfee, Attribution-NonCommercial (http://creativecommons.org/licenses/by-nc/4.0/) CC BY-NC. 
In the first half of this paper, the literature review, the author presents theoretical perspectives for both library anxiety and shame theory. In the second half of the paper, selected comments from library publications are analyzed for hidden shame. Techniques for neutralizing shame are also suggested.

\section{My Experience with Library Anxiety}

As an undergraduate, I had a debilitating fear of the college library. After I was given my first research assignment, I agonized for weeks about how I would conduct the research. I felt certain that other students had already mastered library research methods and that I was far behind everyone else. I worried that, if I asked questions, it would expose how little I knew. I worried that my questions would interrupt the librarian from doing real work. When I finally found the courage to walk into the library, I felt lost. I couldn't think straight or understand the signs. I needed help finding a specific journal, so I carefully prepared my question for the reference librarian. I made my way to the reference desk and I mumbled my question incoherently to the librarian on duty. Terrified, I waited for her response. She clearly understood my question, but she seemed irritated and unimpressed. I sensed that she had already answered my question a dozen times that day. She proceeded to give me clear, simple directions, but I was so panicked I asked her to repeat the directions three or four times. Finally, she raised her voice and very, very slowly repeated the directions. I walked away feeling like a complete idiot. I deeply regretted asking the reference librarian for help and I never approached her again. I found my way to another library, but both my anxiety and the level of service I received were even worse. I finally found success with a third library and eventually graduated from college with honors.

However, my troubles with library anxiety were far from over. After graduation, I landed my first job working in the academic library of one of the most prestigious universities in the United States. My job was to provide one-on-one reference service during the evenings and on weekends. After my first year, I noticed that certain people began to wear on me: the overly apologetic students who never allowed me to speak; the desperate, panicked visitors who could barely grasp the simplest concepts; and the faculty who raged at me whenever we added new technologies or made changes to collections. Feeling protective of my personal boundaries, I developed a steely, icequeen attitude toward these people. Unaware of the phenomenon of library anxiety, I never connected these interactions to my own experiences as a student. Every day, I left work wishing I could show more kindness and tolerance to these users.

To truly change these encounters, I needed to pinpoint the affective barriers and resolve them. I turned to the academic literature for answers. The literature provided important data about the phenomena of these occurrences and how it can be addressed.

\section{Literature Review}

\section{Theoretical Framework: Unacknowledged Shame}

In 1971, the psychologist Helen Block Lewis presented revolutionary research in her book, Shame and Guilt in Neurosis. ${ }^{4}$ As a practicing psychoanalyst, Lewis observed that psychotherapy had failed to help many patients, including some of her own. She conducted an investigation into the psychological states of shame and guilt with the prospect of developing improved therapeutic techniques for patients. She wrote, "One influence impelling me to an inquiry into these psychological states was the small, but nevertheless disturbing, group of patients who had terminated a successful analysis and then surprised me by returning after a few years in even worse psychic condition than when they had originally applied for treatment." ${ }^{5}$ Lewis suspected that hidden factors could be found in the therapeutic relationship because she noted that in general, 
neurotic patients "were highly developed ethically" and generally undertook treatment "with a moral commitment to self-improvement."

Up until this time, psychoanalysis had put little focus on the study of shame; therefore, Lewis did not have a body of work to draw from for her research. She began a quantitative assessment using the Gottschalk method to identify affects in roughly 200 verbal transcripts of psychotherapy sessions. ${ }^{7}$ A qualitative analysis was also used to count the occurrence of affects and their symptoms. To her surprise, the shame affect outnumbered all other affects combined. ${ }^{8}$ She also found that shame played a profound role in the symptom formation of anxiety, depression, and obsessive thinking. The results of her study showed that both patient and therapist never identified shame when it was clearly present. More important, Lewis was able to trace the sequences of emotions to the origins of neurotic symptoms. She wrote, "Difficulties in identifying one's own experience as shame have so often been observed that they suggest some intrinsic connection between shame and the mechanism of denial." ${ }^{\prime 9}$ Lewis's data revealed two types of unidentified shame: 1) overt shame, which is slightly available to the consciousness, but only to the extent that a person would claim to feel "'lousy' or 'tense' or 'blank'"; and 2) by-passed shame, which is completely denied and felt as a "'wince,' 'blow,' or 'jolt."'”10

No one understands and appreciates the value of Lewis's work more than the sociologist Thomas Scheff. Upon reading her work, he immediately recognized that Lewis's findings were applicable to more than the just the patient-therapist relationship. ${ }^{11}$ Her data shed light on the emotional factors taking place in most social conflicts-factors that had long been attributed to feelings of anger or fear. A profound implication of her work, according to Scheff, is the discovery that both guilt and resentment are "shameanger variants; guilt is a shame-anger sequence in which the anger is directed back at the self, and resentment is a shame-anger sequence in which the anger is directed out at another."12

The most surprising discovery of Lewis's study was the invisibility of shame. This is an issue that challenges researchers today, specifically in the area of psychology, where the shame word is controversial and still making its way onto the academic radar. How do you measure something that neither the subject nor the researcher can define or acknowledge? In a recent psychology publication on the topic of shame and aggression, a group of researchers admitted, "One of the major challenges in the study of shame is the assessment of unacknowledged shame feelings." ${ }^{13}$ Scholars in sociology believe that the invisibility problem may be cultural, and this is evident by our vernacular usage of the word shame. ${ }^{14}$ Research on the shame affect has gained momentum in the last ten years, but many scholars never use the shame word in their papers even when they are writing about shame. Regarding academic research and everyday language, though shame "continues to exert a powerful influence," Scheff writes, "it is still close to being unspeakable and unprintable."15

\section{The Purpose of Shame}

The purpose of shame is simple, yet widely misunderstood. Shame is a normal, everyday emotion that continually monitors the strength of our social bonds. ${ }^{16}$ The biggest misconception about shame is that it represents dysfunctional or unhealthy thinking. Shame feels dysfunctional because, when it is activated, it reduces joy, interest, or excitement. ${ }^{17}$ It then replaces positive emotions with negative, self-conscious emotions where one feels diminished. Physiologically speaking, shame is designed to have maximum power over other emotions so it can call one's attention to oneself. Shame is a silent emotion; but, if it could speak, it would say, "Freeze. Stop feeling good and take a look at yourself." 
The psychologist Paul Gilbert believes shame has evolutionary origins in that it regulated status, social rank, and submissive behavior. ${ }^{18}$ He explains, "Humans are social animals who are strongly predisposed to live in close proximity to one another... Indeed, the evolution of nearly all salient social behaviors (e.g., acquiring mates, forming alliances and gaining status) took place in the confines of group living."19

Cultural influences play a significant role in how we adapt to the shame affect. In some East Asian, collectivist societies, shame is used openly to control social behavior; feeling it publicly can be a positive attribute. ${ }^{20}$ Harmony within the community is valued more than individual accomplishments. A modern, individualistic culture views shame as a sign of failure and considers individual success to be the greatest achievement. ${ }^{21}$ This is where shame becomes complex for modern societies. Unlike other self-conscious emotions, shame is primitive and no amount of social conditioning or cognitive influences can remove it from humans. ${ }^{22}$ Shame has a biological function, regardless of how we define it.

As a sociologist, Scheff argues that shame is the "premiere social emotion" and the "glue which holds relationships and society together." ${ }^{23}$ Caring for family and building communities depends on secure social attachments. In human relationships, the shame affect signals alienation, disconnection, loss of security and safety. When an action is taken that threatens a social bond, shame is the biological response to this threat of separation. Scheff explains:

Shame arises in an elemental situation in which there is a real or imagined threat to our bonds; it signals trouble in a relationship. Since an infant's life is completely dependent on the bond with the caregivers, this emotion is as primitive and intense as fear. The point that shame is a response to bond threat cannot be emphasized too strongly, since in psychology and psychoanalysis there is a tendency to individualize shame, taking it out of its social matrix."24

Lewis's work does not attempt to clarify the phenomenology of shame per se, but rather shame that is disguised, misidentified, or unacknowledged. Unacknowledged shame disrupts and threatens the stability of normal relationships. Shame states that are completely repressed can be traced to the symptom formation of depression, anxiety, obsessive behavior, and other neurotic behaviors.

\section{Library Anxiety}

Fifteen years after Lewis published her pioneering work, Constance Mellon, a professor of library science, formally introduced the theory of "library anxiety" and published the results of her study for an article in College \& Research Libraries. ${ }^{25}$ Mellon's research interests began when she taught bibliographic instruction to incoming freshman at East Carolina University. She wrote:

As I spent more time with the college students I was attempting to instruct, I became increasingly aware of their discomfort in the library. What I originally perceived as a lack of interest and motivation began to seem more like a phobia. Students would do anything to get out of the library. They would spend vast sums of money photocopying materials they hadn't even read or would leave empty-handed when information they wanted was on microfilm. ${ }^{26}$

Mellon analyzed the personal writings of students from twenty English composition courses over a two-year period..$^{27}$ The students documented their experiences, feelings, and attitudes while using the academic library. Mellon's findings are remarkable, 
because she not only pinpoints shame specifically, but she describes it as a recursive, emotional state that keeps the sufferer trapped. Library anxiety, as outlined by Mellon, has these features:

1. Students generally feel that their own library-use skills are inadequate while the skills of other students are adequate.

2. The inadequacy is shameful and should be hidden.

3. The inadequacy would be revealed by asking questions. ${ }^{28}$

Mellon's observations distinguished fear from shame at a level that is very difficult for most researchers and clinicians. Freud wasn't even able to do this - by the end of his career, he attributed all anxiety to sexual frustration. ${ }^{29}$ In the students' journals, Mellon found a high frequency of terms such as scary, overpowering, lost, helpless, confused, and fear of the unknown. ${ }^{30}$ She was able to connect these feelings to a self-conscious crisis, rather than just straightforward fear. The students describe a panic-like state regarding their own abilities, often expressing bewilderment: "It was like being in a foreign country and unable to speak the language." ${ }^{\prime 31}$

Mellon did not begin her study with a concept of library anxiety; the theory was developed from the data she received in the students' journals. ${ }^{32}$ Gillian Gremmels points out that it was Mellon's unconventional but rigorous approach to the research that was needed for this discovery to happen. She writes, "Although Mellon was not the first to discuss or recommend qualitative methods ... her study confirmed the value of this type of inquiry for hearing authentic voices and discovering previously unknown constructs and phenomena." ${ }^{33}$

LIS scholars at this time began taking a closer look at the negative emotions students experienced while seeking information for research assignments. Carol C. Kuhlthau incorporated a theory that doubt, confusion, and a feeling described as "a threat" were normal during the initial stages of research. ${ }^{34}$ This affective disruption or threat occurs when new, confusing information conflicts with previously held beliefs. Narratives in Kuhlthau's 1988 study indicate that this threat begins at the moment a research project is assigned - Kuhlthau writes, “One student revealed, 'When I hear about an assignment, personally I just get upset.' Another described feeling 'a spontaneous type of fear.'" 35

\section{Affective Barriers in Library Anxiety}

Six years after Mellon's article was published, researchers in the LIS field began to build on her ideas. In her dissertation, "The Development and Validation of the Library Anxiety Scale (LAS)," Sharon Bostick raised the question, "Can a valid and reliable instrument be developed to measure Mellon's theory of library anxiety?"36 With this question in mind, she designed the first quantitative analysis tool for library anxiety. She used a factor analysis method to reduce the number of variables and structured

\begin{tabular}{|l|c|c|c|}
\hline \multicolumn{4}{|c|}{ TABLE 1 } \\
Description of Factors Derived from First Test \\
\hline \multicolumn{1}{|c|}{ Factor Description } & $\begin{array}{c}\text { Number } \\
\text { of Variables }\end{array}$ & Eigen Value & $\begin{array}{c}\text { Percent of Explained } \\
\text { Variation }\end{array}$ \\
\hline 1. Barriers with Staff & 15 & 10.93 & 25.4 \\
\hline 2. Affective Barriers & 12 & 3.44 & 8.0 \\
\hline 3. Comfort with Library & 8 & 3.19 & 7.4 \\
\hline 4. Knowledge of the Library & 5 & 2.61 & 6.1 \\
\hline 5. Mechanical Barriers & 3 & 2.09 & 4.9 \\
\hline \multicolumn{1}{|c|}{ Total } & $\mathbf{4 3}$ & & $\mathbf{5 1 . 8}$ \\
\hline
\end{tabular}


their relationships so that components of library anxiety could be classified and measured. The final analysis yielded five meaningful factors which determined $51.8 \%$ of the variation in library anxiety, shown in table $1 .^{37}$

Drawing from the concepts developed by Mellon, these factors became the dimensions of library anxiety used for the LAS. The factor with the biggest variation in library anxiety is barriers with staff, because, as Bostick noted, "There is a tendency for students to view library staff, particularly librarians, as intimidating and aloof. The librarian is also perceived as too busy to provide assistance in using the library." ${ }^{38}$

Conceptually, all five factors could be categorized under one dimension: affective barriers with the staff. During the creation of the LAS, statements were formulated to determine the different factors of library anxiety. Five sample statements taken from the factor analysis process are listed below. Notice that, in each statement, there is an emotional barrier with the staff that prevents the student from asking for help:

1. Barriers with the staff: Librarians don't have time to help me.

2. Affective barriers: I feel like I am bothering the reference librarian if I ask a question.

3. Comfort with the library: I don't understand the library's overdue fines.

4. Knowledge of the library: I want to learn to do my own research.

5. Mechanical barriers: The computer printers are often out of paper. ${ }^{39}$

Feelings of inadequacy, confusion, shyness, and frustration are all emotional barriers, and they are all dependent on the student's relationship with the staff. For example, if a student feels frustration or anxiety because printers are "often out of paper," this is because he feels his research needs are not being met by the library staff. The majority of the statements used for all five factors reveal obvious disconnections between students and staff. Unhindered, healthy communication between the student and librarian would resolve many conflicts in library anxiety, but the emotional barriers are just too powerful. Why? Because the innate affects, emotions, and feelings that drive library anxiety are complex and insidious.

The library research process today is much different from that of the 1980s and 1990s, and the LAS has been adapted for different environments and technology including recent instruments created for Chinese and Polish libraries. ${ }^{40}$ Doris Van Kampen-Breit developed the Multidimensional Library Anxiety Scale in 2004 because she wanted to know more about the changing feelings of students during the information-seeking process. ${ }^{41}$ Even in the most recent surveys, however, the negative emotions that students express are indistinguishable from the earliest studies. Below are words and phrases extracted from student narratives during library anxiety studies conducted internationally from 2010 until 2016.

unexplained feeling akin to fear; angry and depressed; you feel you want to cry!; hate entering the library; feeling of being ignorant; frightening place. ${ }^{42}$ apprehensive; I should be more aware; Jesus I should be taking notes. ${ }^{43}$ lost, frustrated, I try as much as possible to stay away. ${ }^{44}$ I'm stumped/overwhelmed; i'm so sorry!; Oh, I don't want to be a nuisance; Sorry for all the questions :). ${ }^{45}$ so scary and overpowering for me; unable to understand what's going wrong; failure each time; insecure and helpless; terrified; My God!; like being in a desert where you are unable to find the right way to move. ${ }^{46}$

\section{Defining Innate Affects, Emotions, and Feelings}

Differing opinions and theories persist about the number of innate affects that humans possess, and some scholars argue that guilt, shyness, and embarrassment are distinct affective experiences outside the scope of the shame affect. ${ }^{47}$ Silvan Tomkins, the psychologist who developed the innate, biology-based affect theory determined that humans possess nine innate affects. ${ }^{48}$ In his theory, embarrassment, shyness, self- 
contempt, and guilt all originate within the psychobiology of the shame affect-they are derived from shame and not separate from it. ${ }^{49}$ Donald Nathanson, a psychiatrist and Tomkins scholar, explains that, while shame involves a focus on the self and guilt involves the awareness of harming others, they both share the negative experience of exposure. ${ }^{50}$ Piers and Singer distinguish guilt and shame in a similar way, "Whereas guilt is generated whenever a boundary... is touched or transgressed, shame occurs when a goal....is not being reached. It thus indicates a real 'shortcoming.' Guilt anxiety accompanies transgression: shame, failure." 51

The nine innate affects, each containing a range of intensity:

1. Surprise-Startle

2. Joy-Enjoyment

3. Distress-Anguish

4. Interest-Excitement

5. Anger-Rage

6. Fear-Terror

7. Contempt-Disgust

8. Shame-Humiliation

9. Dissmell-Disgust ${ }^{52}$

Affects are physiological responses of the body that produce biological symptoms. They are connected to the most primitive part of the brain and are almost always displayed on the face and very quickly, for just a few hundredths of a second. Feelings are the awareness of affects and therefore require a more complex level of consciousness that humans possess. Emotions require an information retrieval system in the brain. They rely on the feelings and affects experienced in previous events. Nathanson writes, "An affect lasts but a few seconds, a feeling only long enough for us to make the flash of recognition, and an emotion as long as we keep finding memories that continue to trigger that affect. ${ }^{53}$

In Tomkins' prosaic work, Affect Imagery Consciousness, he dedicates hundreds of pages to the analysis of shame because no other affect contains mechanisms as powerful and complex as shame. Tomkins writes, "How can loss of face be more intolerable than loss of life? How can hanging the head in shame so mortify the spirit? In contrast to all other affects, shame is an experience of the self by the self. At that moment when the self feels ashamed, it is felt as a sickness within the self." ${ }^{54}$

\section{The Social Phenomenon of Library Anxiety}

Understanding the social nature of library anxiety is crucial to understanding its relationship to shame as opposed to fear. Shame is the generator of fear if that fear is about a negative evaluation of the self. When the feeling of shame stays both unresolved and unconscious, it generates more fear, more shame, anxiety, and so on. ${ }^{55}$

In the mid-1990s, Qun Jiao and Anthony Onwuegbuzie began a series of research investigations into library anxiety to further validate Mellon's theory. They verified it to be a situation-specific type of anxiety as well as socially driven. ${ }^{56}$ By employing different psychological instruments including the LAS, they produced a body of research that shed light on the nature, etiology, and consequences of library anxiety. They determined that most library anxiety sufferers are not permanently afflicted with anxiety: that is, anxiety is not inherent to their personality. ${ }^{57}$ This is significant in that academic-related shame, such as library anxiety, test anxiety, and math anxiety, all share a similar social experience in that these evaluation anxieties are time- and situation-specific. ${ }^{58}$

\section{Perfectionism and Procrastination}

Perfectionism and procrastination are traits found in students with high levels of library 
anxiety; interestingly, in their respective fields, both shame scholars and library anxiety scholars believe these traits to be self-protective measures against the prospect of negative evaluation. ${ }^{59}$ They also believe these traits to be intrinsically linked. Perfectionists visualize impossible standards for themselves, thereby creating a high probability of failure, which in turn leads to procrastination to avoid failure and its accompanying shame. ${ }^{60}$ Procrastination is a serious problem for 25 percent of adults. ${ }^{61}$ For college students, this number doubles and becomes more severe for students who have researchheavy coursework. ${ }^{62}$ In their article, "Procrastination: A Means of Avoiding Shame and Guilt," Ronda Fee and June Tangney found that procrastination is motivated by shame opposed to guilt due to the fact that the avoided tasks almost always correlate to one's worth. ${ }^{63}$ They also note that procrastination is more problematic for adults who have higher levels of self-consciousness while out in public.

In the academic environment, the threat of negative evaluation (that is to say, shame) always looms. It is an inevitable aspect of academic life. Why do some students have more affective-laden dysfunction than others? Jiao and Onwuegbuzie found that students with higher levels of socially prescribed perfectionism experience more library anxiety. ${ }^{64}$ This particular style of perfectionism ranks highly for both library anxiety researchers and shame researchers. ${ }^{65}$ Unlike the self-oriented perfectionism, which is directed at the self by the self, or other-oriented perfectionism, which is directed at others by the self, socially prescribed perfectionism is based on a person's belief that unrealistic standards are set for him by others. ${ }^{66}$ Researchers in psychology have found an undeniable association between shame-proneness and socially prescribed perfectionism." ${ }^{67}$ More important, unlike the other types of perfectionism, socially prescribed perfectionism has been linked to depression, anxiety, and obsessive-compulsive behaviors.

\section{Identifying Hidden Shame: The Markers}

The shame affect is so physically disturbing that we have developed an infinite list of synonyms to disguise it and lessen its intensity. Taking a look at the cognates that represent shame can help identify it in library discourse. In her article, "Identifying Shame and Anger in Discourse," Suzanne Retzinger examines the vocabulary that disguises shame in everyday occurrences. ${ }^{6}$ She writes, "Shame refers to a family of emotions with many variations, from social discomfort and mild embarrassment to intense forms such as humiliation or mortification." ${ }^{69}$ Retzinger provides a list of shame synonyms and shame markers that are commonly used to mask the shame word:

Direct indication: embarrassed, humiliated, chagrined, ashamed, mortified, and so on.

Abandonment, separation, isolation: Statements that indicate feelings of not belonging or otherwise being separated from significant others. Examples: alienated, alone, deserted, detached, distant, disconnected, divorced, dumped, estranged, ostracized, rebuffed, rejected, split, withdrawn.

Inadequate: Statements that reveal that one feels one does not measure up to one's own or other's ideal image. Examples: defenseless, deficient, exposed, failure, inept, helpless, impotent, inferior, insecure, oppressed, powerless, shy, stupid, unable, uncertain, unfit, unsure, worthless.

Ridicule: Words or phrases about being emotionally hurt or threatened by another person; put down or made to look foolish or different. Examples: absurd, asinine, 
bizarre, defeated, dejected, foolish, freak, funny, hurt, idiotic, injured, intimidated, offended, ruined, strange, upset, weird, wounded.

Discomfort: References to social setting; social-emotional discomfiture as referred to by Goffman (1967). Examples: antsy, fidgety, hyperactive, jittery, jumpy, nervous, restless, tense, uneasy.

Confused/indifferent: Statements that indicate muddled thought processes or absence of fluster in an emotionally arousing situation; momentary forgetting (Lewis, 1971). Examples: aloof, blank, dazed, empty, hollow, spaced, stunned. ${ }^{70}$

Scheff and Lewis characterize hiding behaviors in two ways: verbal and physical. Verbal involves behaviors such as stammering, repetition of words, mumbling, pausing, blushing, eyes averted down, and lowering the voice. Nonverbal forms suggest physical hiding; averting or lowering the gaze to escape the gaze of the other, hiding behind a mask-like blush, and hiding the meaning of speech and thoughts behind speech disruption and inaudible speech." ${ }^{\prime 71}$

\section{Identifying Shame in Users' Comments \\ Method}

This analysis is a theoretical conceptualization of the well-documented phenomenon of library anxiety. The author integrated theories from psychiatry, sociology, psychology and library science into concepts for analyzing real world library narratives. This was done in three steps:

1. The literature review covered theoretical perspectives, supported by empirical data in the academic literature.

2. The paper developed a new theory - based on the theories of Lewis and Mellon - that unacknowledged shame is the emotional basis of library anxiety.

3. The paper bridged theory and observation, revealing shame in the spoken and written language of library-anxious users and staff.

Because this was a theoretical and interpretive analysis, the study approached each narrative on the basis of the context and vocabulary of the speaker.

\section{Data Collection}

The author conducted a search for LIS publications containing the quoted text (comments) of library users and staff, then divided these comments into two categories of unacknowledged shame: bypassed shame and overt shame (see illustration 1). While examining the LIS literature, the author looked for language markers signaling the threat of negative evaluation, alienation, and high conflict. After somewhat fruitless attempts to find narratives with bypassed shame (such as expressing irritation, rage, or humiliation), the author extended the search to LibQual surveys posted on library websites. In total, the author drew on eight comments for analysis: four user comments from the LIS literature, including both spoken and written narratives; three user comments from LibQual surveys published on library websites; and one librarian's opinion piece.

\section{Concepts}

The author applied Lewis's two types of unacknowledged shame (overt and bypassed) to users with classic library anxiety and users with high-conflict anxiety, respectively. Two techniques for neutralizing unacknowledged shame are introduced: attunement and leveling. These are not meant as the only techniques, but they are important in that they reveal much about the specificity and power of the shame affect. 


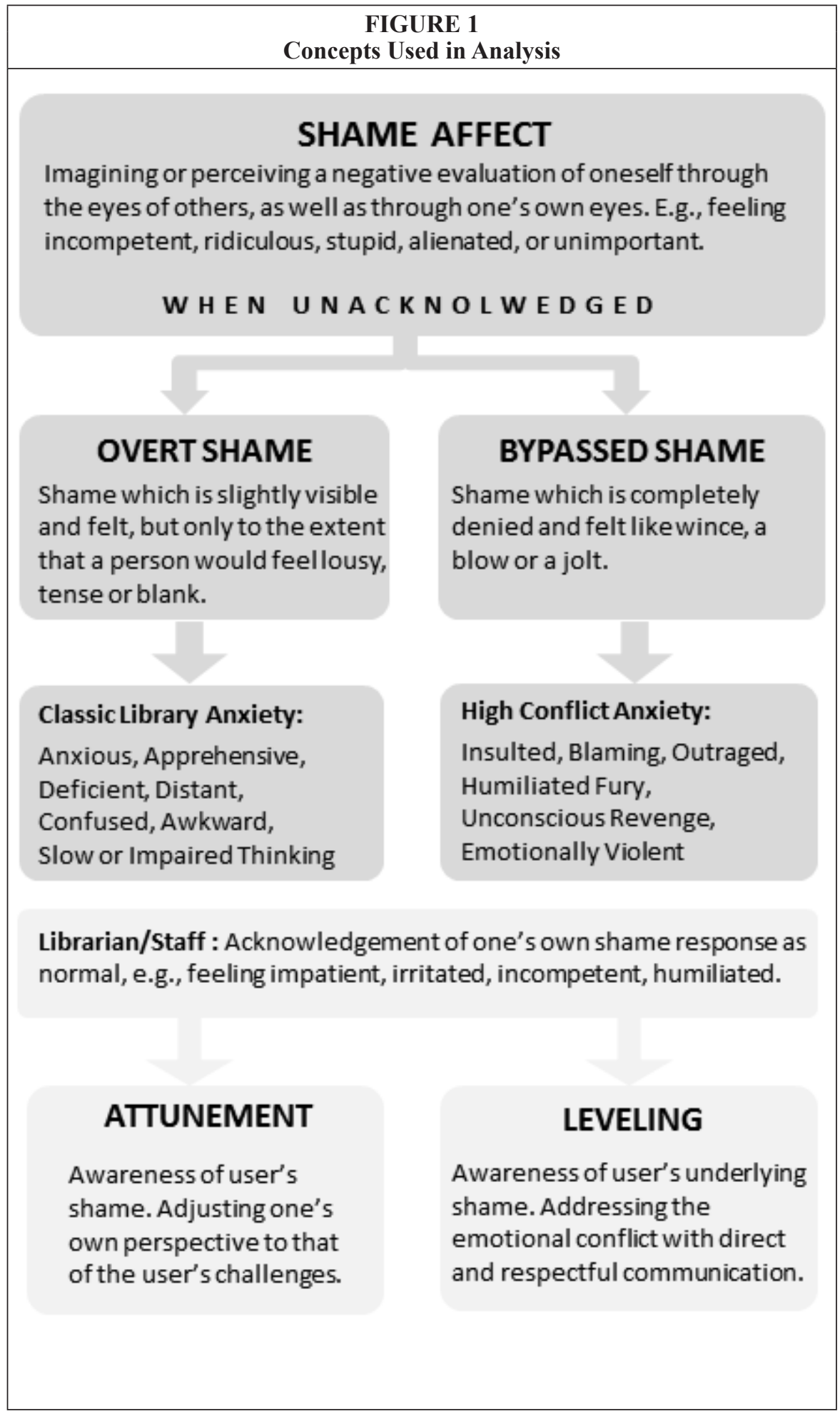




\section{Acknowledging the Shame Affect in Library Anxiety}

Library service interactions are a stimulus for shame; whether it is real or imagined, there is always the risk of being negatively evaluated. Most librarians and staff who have provided library service have witnessed the awkwardness of the student who is unsure of how to phrase a question. The smallest of tasks, such a placing a book on the counter to be checked out, can elicit shame. Like most innate affects, shame is contagious; because of this, staff can unknowingly respond to shame with shame by showing confusion, disapproval, indifference, irritation, or disrespect.

A severe shame state such as library anxiety is a collective experience. Whether it is through avoidance, contribution, reaction, reputation, or denial, the librarian and library are integrated into the emotional experience of the student. Library anxiety cannot exist without library staff being the imagined "other" of the negative evaluation. This does not mean that blame should be assigned to the library staff, because these emotions are unseen by both staff and student as demonstrated in this comment taken from a LibQual survey at the University of Illinois at Urbana-Champaign:

The library staff at the libraries at Urbana-Champaign have been very nice to me during my brief visits when I am on campus on other missions. However, I still feel like a stranger to the library and it is hard to access electronic journals via a field station/Extension. ${ }^{72}$

Although it appears to be a journal access issue, he prefaces his problem with "However, I still feel like a stranger in the library," which indicates he feels disconnected and alienated from the library culture (in other words, staff). This is an emotional barrier that prevents him from resolving his problem while in the library. This affective barrier stems from the shame affect. Feeling like a stranger is more connected to the shame affect than any other affect.

Social and linguistic challenges make the shame affect difficult to identify as an emotion. Shame is felt by the observers, however, sometimes more strongly than the person who is experiencing shame. As Lewis explains, in all areas that one wishes to escape from immediately, "shame has an intrinsic tendency to encourage hiding, so there is a tendency for the observer of another's shame to turn away from it."73

\section{Overt Shame}

A person with overt shame will be unable to articulate the feeling but will exhibit visual symptoms such as lowering the voice, sweating, mumbling, and avoiding eye contact. Overt shame can cause a person to feel numb, confused, or anxious. Lewis describes it to be "available to [the] consciousness but the person experiencing it either will not or cannot identify it... An observer may identify that the other person is having a shame reaction, or the person himself may identify it as it is receding, but while shame is occurring the person is unable to communicate the feeling. He often says only that he feels 'lousy,' or 'tense,' or 'blank'."74 At the moment one is aware of this type of shame, it begins to fade.

The following comment is taken from Scott Lee's 2011 library anxiety study of community college students in California. ${ }^{75}$ This student was interviewed after scoring the highest level of anxiety on the Comfort and Knowledge subscales:

I was in here once, and I remember I was on the computer and asked for help from one of the librarians, and it took her awhile to get to me. That's why like, I'm kinda like, apprehensive about asking people. Just because I feel maybe they might be busy or I don't wanna be like a bother for them. I don't know. I just feel like sometimes you can't ask questions. ${ }^{76}$ 
Consistent with Lewis's theory of overt shame, he is somewhat aware of his feelings by stating that he is apprehensive, but this is not enough to allow the shame to diminish. As the hidden shame keeps cycling around, producing more shame and other feelings such as guilt and fear, he eventually becomes numb and slightly indifferent (also indicators of shame). This culminates into the statement, "I just feel like sometimes you can't ask questions." In the context of his need for social interaction, his discomfort and tension could be referred to as "social-emotional discomfiture" in Retzinger's category of shame markers. ${ }^{77}$

In 2008, Nahyun Kwon conducted a mixed-method investigation to study the association between library anxiety and critical thinking skills. ${ }^{78}$ Students were asked to write an essay on their past experience using the library. This is a response from one of the participants:

I was intimidated since I had never had to search for books in the library before. I was able to use the computer to find books that I wanted... I had no idea how the library was set up and it was like walking through a maze. I didn't want to ask a librarian for help because I felt foolish. ${ }^{79}$

In Retzinger's category of shame markers, intimidated and foolish are both listed under the category of "ridicule," which are "words or phrases about being emotionally hurt or threatened by another person; put down or made to look foolish or different." 80 The phrase, walking through a maze, indicates isolation and separation, but also shows how the shame is overt; she is confused-losing her ability to think clearly. Frustration and confusion may not seem like obvious signs of shame, but, taken in the context of feeling helpless and powerless, the connections begin to make sense. Feeling helpless, powerless, small, and diminished are shame-based emotions.

Colleen Cook and Fred Heath analyzed the service quality of North American research libraries by conducting sixty interviews at nine different libraries." 81 The participants were professors, graduate students, and undergraduates. Based on the excerpts available, neither the interviewers nor the participants made references to library anxiety. The following comment is important because many librarians are familiar with this type of question - the student will apologize for his question before he asks the question:

Probably five times out of ten, when a student goes to ask a librarian something, they'll say I know this is a really stupid question or I know I should know where to find this book, but... They always preface it with some sort of self-degrading remark, and I think sometimes students are just too embarrassed to admit what they don't know. ${ }^{82}$

Feeling stupid, unsure, incompetent, and inadequate are all signs of classic library anxiety, and they are all indicators of overt shame. The shame is reflected in the belief that one has failed to meet the librarian's basic expectations of library knowledge. Compounding that shame would be revealing it to the librarian. Lowering one's status with deference or humor demonstrates more awareness of shame. Humor is a positive way to alleviate shame, but degrading one's status in a serious tone, as in "this is a really a stupid question..." would indicate a person is unaware of the compounded shame. The authors of this study were not expecting emotional issues to take precedence over all other areas of service. They wrote, "In the analysis, the mass of content relating to affective issues is revelatory. Interviewees spent more time expressing their concerns and expectations for the delivery of respectful and caring service than other factors." ${ }^{13}$ 


\section{Attunement: Neutralizing Overt Shame}

While interacting with another person, attunement requires shaping one's own response to the other person's perspective. The goal is to maintain a respectful and concerned attitude. It is not about agreeing or disagreeing with another person's point of view. Attunement demonstrates the opposite of shame; it is a genuine understanding for another person's position without judgment. It brings security in a relationship, while shame weakens and separates. According to Tomkins, shame is the interruption of our positive feelings, which include interest, excitement, and joy. ${ }^{84}$ When a library user feels unsupported, this will evoke shame; in turn, this will reduce his interest in the library, as seen in this student's comment:

I've just never been treated very nicely by any of the librarians. Whether that be at the circulation desk, or during a classroom session. There is a certain air about them, arrogance perhaps, that really pushes me away from using great services offered to their fullest extent. ${ }^{85}$

This comment doesn't indicate that the library staff acted inappropriately, and it is not included to incite blame. This is a perfect example of how shame produces alienation. Whether the librarian acted out of shyness or arrogance (both shame-based attitudes), it still produces the same effect-it creates distance. Many scholars agree that shame's opposite emotion is based in a feeling of connectedness, as Lee et al. explain: "When operating optimally, shame and support facilitate our making contact with others. Support happens when others are interested in being with us in ways that we seek or discover that we like; shame signals us to pull back when we perceive (correctly or otherwise) that our desires are or may be unsupported." ${ }^{86}$

Identifying a library user's shame does not require counseling, psychoanalyzing, or treating the person as a fragile therapy patient. If a user's behavior indicates the presence of shame, it can help signal an awareness of one's own shame, or in many cases, the power to prevent one's own shame response from manifesting. Identifying one's own shame opens the door for attunement. As Scheff points out, "The failure of attunement sets the stage for shared shame. If shame is acknowledged, the threatened bonds can be repaired and solidarity sustained. If shame is not acknowledged, separation and/or destructive conflict are likely to occur." ${ }^{87}$

When a user approaches a librarian with a sincere, awkward apology before asking his question, an attuned response would identify the user's shame as logical, given his situation. Attunement would also include identifying one's own shame response as normal (such as a strong urge to correct the student or to ignore the awkwardness). One way to respond is to say, "You came to the right place and you are asking all the right questions." If a student's shame causes him to apologize for wasting a librarian's time, as in, "I am so sorry to bother you...," an attuned response might be, "I am so glad you came to me with your question, because helping library users like you is the best part of my day." "Best" could be interchanged with "interesting," "rewarding," or any term that lets the student know his library needs are important to the librarian.

\section{Bypassed Shame}

Bypassed shame as Lewis describes it is a "lightning-speed sequence from an evoked state of shame almost simultaneously into a humiliated fury and thence into guilt for what is processed by the person as forbidden anger-unjust, wrong, or inappropriate anger." ${ }^{88}$ While overt shame produces silent, painful feelings of inadequacy and inferiority, bypassed shame is felt like a jab or a slap in the face. At the moment the hostility is expressed, the shame-humiliation affect has already preceded it. The hostil- 
ity is usually directed outward. Scheff and Retzinger write, "Normal anger, when it is not intermixed with shame, is usually brief, moderate, and constructive, serving to call notice to adjustments that are needed in a relationship." ${ }^{89}$ Shame-laden anger is much more destructive and difficult to resolve.

There is no shortage of material in the library literature on how to deal with angry users. Much of the literature takes a common-sense approach for reducing negative interactions with users, such as attentive listening, creating better policies, and adding more training for staff. An oversight in the literature is that customer-service advice is typically designed around the concept of the difficult or angry user. It rarely, if at all, focuses on the shame or humiliation felt by librarians. Below are comments written by a library staff respondent on a LibQual survey:

\section{I fail to understand or sympathise with the insecurity complex so rife among today's librar- ians. As an adult library user, I don't need a "kewl" blue-haired pal to help me discern bad information from good, or belly dancers to keep me entertained. What I need and am paying for with my taxes is a (once) strong collection of print materials, the older and more unfashionable, the better. Inasmuch as you have determined that your mean user is an adolescent with $A D H D$, you have chosen to snub users who have already developed research skills and interests outside of competitive vomiting in late February. I sincerely hope that a reappraisal of the American educational system will reveal your malfeasance and mismanagement of a once-great library for the gross act of vandalism that it is..$^{90}$}

Upon first reading, he seems to be expressing anger or contempt, but the revealing shame marker is "snub," in the phrase, "you have chosen to snub users." This is a shining example of bypassed shame. Shame is indicated in the perceived rejection and betrayal he feels. His shame is completely repressed. His phrasing and word choices are meant to degrade the student users and the librarians who serve them, such as, adolescent with $A D H D$, competitive vomiting, malfeasance, mismanagement, and gross act of vandalism. This is all retaliation for the perceived insult/injury of being rejected.$^{91}$ Shame scholars refer to this kind of shame-anger retaliation as "unconscious revenge" or "malevolent intentions," and they consider it to be the strongest and most destructive type of anger. ${ }^{92}$

In a study done by Justina Osa, "The Difficult Patron Situation: Competency-Based Training to Empower Frontline Staff," the staff were asked, referring to the difficult user, "How do they make you feel?" 93 Seventy percent of the staff identified feeling "inadequate" and "incompetent" when dealing with difficult people in the library. ${ }^{94}$ It is important to note that both inadequate and incompetent are shame markers. Osa also noted that library staff gave different answers to many of the questions in oral discussions following the survey. Many respondents said difficult users made them feel confused and less willing to use all available resources to assist them. ${ }^{95}$

Retaliation directed at library users can be a long, cumulative process where, over time, the staff's humiliated feelings find their way into library policies. These policies may become harshly punitive and degrade the perception of the user. If a library service area develops a culture that is rife with shame, then viewing library users as crazy, bad, or stupid becomes the norm. Mary Beth Chappell Lyles, a law librarian at Emory University, subtly correlates the symptoms of narcissistic personality disorder (NPD) to her high-conflict users in the article "Neutralizing Conflict: Counseling Techniques for Law Librarians." 96 Lyles discusses the difficulty in dealing with the emotions of library users who need legal assistance, many of whom work in the legal profession. In a section of her paper titled "The Narcissist on the Other Side of the Desk," she uses an excerpt from Psychology Today to describe symptoms related to NPD: 
anger, shame, or humiliation in response to criticism; exaggerated sense of self-importance; "takes advantage of others to reach his or her own goals"; exaggeration of achievements and talents; "entertains unrealistic fantasies about success, power, beauty, intelligence, or romance"; expects favorable treatment unreasonably; needs constant attention and reinforcement from other people; becomes jealous easily; ignores or is oblivious to the feelings of others, basically an empathy deficit; obsessively self-interested; and pursues goals that are primarily selfish. ${ }^{97}$

Publishing a paper that implies her library users exhibit traits of a personality disorder may be a reaction to the shame-humiliation that she has felt over time. However, in her defense, many scholars believe that narcissism is a response to chronic shame, so it is likely that she is dealing with the highest levels of bypassed shame in terms of library anxiety. According to Nathanson, living in a chronic state of shame does not allow us to form a positive sense of self, so we adopt an ideal self with limitless talent and capabilities. ${ }^{98}$ Anyone who inadvertently threatens a narcissist's ideal self, including a well-meaning librarian, may unleash a severe state of bypassed shame. Interestingly, the technique that Lyles suggests for dealing with high-conflict patrons (such as adopting attitudes of empathy, attention, and respect) are emotions that speak directly to the shame affect.

The final example of bypassed shame is written by a student complaining about the service he received after returning a charger:

I asked a simple question about how to pay for a late fee for mac chargers when I was returning mine late, because I had never done that before, and I had assumed you could pay at the library but the woman I talked to was very rude and acted as if I had stolen something, when I had just held onto the charger overnight since one of the work study students wouldn't allow me to re-check the charger out at 10 p.m. at night since my own personal charger was broken. I was very appalled by this type of service, since the library should be understanding if a personal charger is broken, and should not be rude or grumpy towards answering a simple question. ${ }^{99}$

In this example, verbal references to shame are indicated with, "acted as if I had stolen something." The student is evaluating himself negatively through the eyes of the staff. He feels the staff view him as a thief. This causes him to launch into criticism of the policy to prove he is not a thief. Library conflicts involving policies and service attitudes are difficult to resolve, because the emotions are rarely identified or viewed as the source of conflict.

\section{Leveling: Neutralizing Bypassed Shame}

During interactions where one party is overwhelmed with shame and guilt for his transgressions, the communication technique of leveling can help neutralize shame. Leveling exposes one's immediate thoughts, feelings, and expectations to others without insult or injury. What makes this difficult, according to Scheff, is that it requires a direct and respectful tone in the delivery; most people are too direct and disrespectful, or too respectful, but indirect. ${ }^{100}$ Scheff explains why leveling is so effective:

...we often assume that some topics are automatically dangerous while others are completely safe. As it turns out, this is not the case; we can get into trouble with safe topics and escape trouble with dangerous ones, depending not only on what we say but how we say it... nonverbal elements like tempos, loudness, facial expression, and other bodily gestures are often as important as words. ${ }^{101}$ 
Most people are reluctant to level because emotions are rarely, if ever, identified as the source of conflict. In the situation with the charger, leveling would sound like this: "Your actions make sense given your situation and I want to find a way to help you. Let's see what we can do within the rules I must follow. How does that sound?" Disapproval is not harmful if it is communicated in a respectful manner. ${ }^{102}$

Bypassed shame is usually directed outward, and those on the receiving end may retaliate with an equal amount of anger. Intractable conflicts occur when shame is completely hidden from both parties, and the topic will usually mask the true problem. ${ }^{103}$ For example, the user who remarked that he didn't need a "'kewl' blue-haired pal” will most likely stir up disturbing feelings for the reader. How is it possible to feel respect for this person with so much hostility directed at librarians and students? The first step is to identify one's own shame response as normal (for example, insulted, sickened, or humiliated). Next would be to identify the user's underlying shame reaction as normal: he feels abandoned and unimportant. One way to level with this user is to say, "Yes, getting older and seeing beloved traditions change is difficult. There are moments when it feels like a death has occurred. You are not the only person to feel this way. It is inherent to the human condition-even Aristotle and Socrates complained about the younger generation being lazy and unintelligent."

\section{Future Directions: Disarming Hidden Shame}

In a recent study, Doris Van Kampen-Breit and Rachel Cooke found that 40 percent of students believe that librarians are too busy to help them, and they estimated that 30 percent of students leave the library without their desired resources. ${ }^{104}$ Shame is a painful and isolating experience, and most users who are in these shame states believe they are the only ones with these feelings. On a micro level, every library anxiety survey and outreach initiative is an effort to normalize shame and bring students out of isolation. These efforts are a prosocial way to deal with shame.

Institutional shame that contributes to library anxiety is a conundrum: Kuhlthau's research shows that students naturally experience shame during the initial stages of research, and this is needed in order to become teachable; but studies also show that, if the shame is too compounded and paralyzing, the learning process is disrupted. ${ }^{105}$ The key to locating destructive shame is to look for institutional behaviors that alienate users. For example, what kind of attitude does an institution communicate to its users? Does the library terminology alienate users or does it bring them closer to the library resources and librarians? Do policies embrace a belief that library users are trying to improve their lives, or do the policies punish users for trying to take advantage of the system? Most important, when confronting the manifestations of hidden shame, it is beneficial to use the shame word openly. As unpleasant and disturbing as this word is to hear (such as library shame), using it is a form of empowerment. Avoiding the shame word is an activating agent of shame. The simple act of acknowledging shame resolves many of its destructive effects-effects that would otherwise persist when it is hidden from our awareness. When shame is specifically identified, it can be replaced with attitudes and behaviors that strengthen bonds with the community.

\section{Conclusion}

Recent scholarship on shame theory has revolutionized the study of human behavior. When library anxiety research is examined using the theoretical framework of unacknowledged shame, affective components begin to surface. LIS scholars have determined that library anxiety is a socially based phenomenon. Analyzing the social emotions that evoke library anxiety is crucial to understanding the role that shame plays. The crux of this hypothesis is that shame emerges as the dominant affect in 
library anxiety when users feel alienated and disconnected from library culture and staff. The social matrix of library anxiety raises new questions that are addressed in this paper: how does library anxiety affect the emotional-relational world of staff and library users; how does it manifest in library service interactions; and how is it resolved when the emotions are identified?

\section{Notes}

1. Charles H. Cooley, Human Nature and the Social Order (New York: Scribner, 1922), 184.

2. Constance A. Mellon, "Library Anxiety: A Grounded Theory and Its Development," College $\mathcal{E}$ Research Libraries 47, no. 2 (1986): 160-65, doi:10.5860/crl_47_02_160.

3. Anthony J. Onwuegbuzie, Qun G. Jiao, and Sharon L. Bostick, Library Anxiety: Theory, Research, and Applications (Lanham, Md.: Scarecrow Press, 2004), 281.

4. Helen B. Lewis, Shame and Guilt in Neurosis (New York: International, 1971).

5. Ibid., 12.

6. Ibid., 14 .

7. Louis Gottschalk, C. Winget, and G. Gleser, Manual of Instruction for Using the GottschalkGleser Content Analysis Scales (Berkeley: University of California Press, 1969).

8. Thomas J. Scheff, "Shame and the Social Bond: A Sociological Theory," Sociological Theory 18, no. 1 (2000): 84-99, doi:10.1111/0735-2751.00089.

9. Lewis, Shame and Guilt, 196.

10. Ibid., 196-97.

11. Robert Karen, "Shame," Atlantic Monthly 269, no. 2 (1992): 40.

12. Thomas J. Scheff and Suzanne M. Retzinger, Emotions and Violence: Shame and Rage in Destructive Conflicts (Lexington, Mass.: Lexington Books, 1991), 13.

13. Jeff Elison, Carlo Garofalob, and Patrizia Velotti, "Shame and Aggression: Different Trajectories and Implications," Aggression and Violent Behavior 19 (2014): 456, doi:10.1016/j.avb.2014.04.011.

14. Thomas J. Scheff and Steve Mateo, "The S-Word Is Taboo: Shame Is Invisible in Modern Societies," Journal of General Practice 4, no.2 (2016), doi:10.4172/2329-9126.1000217.

15. Thomas J. Scheff, "The Ubiquity of Hidden Shame in Modernity," Cultural Sociology 8, no. 2 (2014): 134, doi:10.1177/1749975513507244.

16. Scheff and Retzinger, Emotions and Violence.

17. Silvan S. Tomkins, Affect Imagery Consciousness: The Complete Edition: Two Volumes (New York: Springer Publishing Company, 2008), 353-54, available online from ProQuest ebrary [accessed 7 February 2017].

18. Paul Gilbert and Michael T. McGuire, "Shame, Status, and Social Roles: Psychobiology and Evolution," in Shame: Interpersonal Behavior, Psychopathology, and Culture, eds. Paul Gilbert and Bernice Andrews (New York: Oxford University Press, 1998), 99-125.

19. Gilbert and McGuire, "Shame, Status, and Social Roles," 114.

20. S.G. Hofmann, A. Asnaani, and D.E. Hinton, "Cultural Aspects in Social Anxiety and Social Anxiety Disorder," Depression and Anxiety 27, no. 12 (2010): 1117-27, doi:10.1002/da.20759.

21. Ibid.

22. Ryan Nichols, "Civilizing Humans with Shame: How Early Confucians Altered Inherited Evolutionary Norms through Cultural Programming to Increase Social Harmony," Journal of Cognition and Culture 15, no. 3/4 (2015): 254-84, doi:10.1163/15685373-12342150.

23. Ibid., 98.

24. Thomas J. Scheff, “Shame in Self and Society," Symbolic Interaction 26, no. 2 (2003): 254, doi:10.1525/si.2003.26.2.239.

25. Mellon, "Library Anxiety."

26. Constance A. Mellon, "Attitudes: The Forgotten Dimension in Library Instruction," Library Journal 113, no. 14 (1988): 138.

27. Mellon, "Library Anxiety."

28. Ibid., 160.

29. Donald L. Nathanson, Shame and Pride: Affect, Sex, and the Birth of the Self (New York: Norton, 1992), 44; Scheff, "Shame in Self and Society," 251.

30. Mellon, "Library Anxiety," 162.

31. Ibid., 162.

32. Ibid.

33. Gillian S. Gremmels, "Constance Mellon's 'Library Anxiety': An Appreciation and a Critique," College \& Research Libraries 76, no. 3 (2015): 269, doi:10.5860/crl.76.3.268.

34. Carol C. Kuhlthau, "Inside the Search Process: Information Seeking from the User's Per- 
spective," Journal of the American Society for Information Science 42, no. 5 (1991):361-71, doi:10.1002/ (SICI)1097-4571(199106)42:5<361::AID-ASI6>3.0.CO;2-\%23.

35. Carol C. Kuhlthau, "Developing a Model of the Library Search Process: Cognitive and Affective Aspects," $R Q 28$, no 2 (1988): 237, available online at www.jstor.org/stable/25828262 [accessed 8 February 2017].

36. Sharon L. Bostick, "The Development and Validation of the Library Anxiety Scale" (PhD diss., Wayne State University, 1992), 5.

37. Ibid., 63.

38. Ibid., 84 .

39. Ibid., 164-65.

40. Marzena Świgon, "Library Anxiety among Polish Students: Development and Validation of the Polish Library Anxiety Scale," Library \& Information Science Research 33, no. 2 (2011): 144-50, doi:10.1177/0266666915617520; Zhiqiang Song, Shiying Zhang, and Christopher Peter Clarke, "Library Anxiety among Chinese Students: Modification and Application of LAS in the Context of Chinese Academic Libraries," Journal of Academic Librarianship 40, no. 1 (2014): 55-56, doi:10.1016/j.acalib.2013.10.014.

41. Doris J. Van Kampen, "Development and Validation of the Multidimensional Library Anxiety Scale," College \& Research Libraries 65, no. 1 (2004): 28-34, doi:10.5860/crl.65.1.28.

42. K.A. Abusin and A.N. Zainab, "Exploring Library Anxiety among Sudanese University Students," Malaysian Journal of Library \& Information Science 15, no. 1 (2010): 68, 71-73, available online at http://eprints.rclis.org/18221/ [accessed 7 February 2017].

43. Scott W. Lee, "An Exploratory Case Study of Library Anxiety and Basic Skills English Students in a California Community College District" (PhD diss., University of California, 2011): 100, 102, 105.

44. Mónica Colón-Aguirre and Rachel A. Fleming-May, "'You Just Type in What You Are Looking For': Undergraduates' Use of Library Resources vs. Wikipedia," Journal of Academic Librarianship 38, no. 6 (2012): 394, doi:10.1016/j.acalib.2012.09.013.

45. Tammi M. Owens, "Communication, Face Saving, and Anxiety at an Academic Library's Virtual Reference Service," Internet Reference Services Quarterly 18, no. 2 (2013): 155, 157, doi:10.1 080/10875301.2013.809043.

46. Muhammad Asif Naveed, "Exploring Information Seeking Anxiety among Research Students in Pakistan," Libri: International Journal of Libraries \& Information Services 66, no. 1 (2016): 76, doi: 10.1515/libri-2015-0047.

47. June P. Tangney, Rowland S. Miller, Laura Flicker, and Deborah H. Barlow, "Are Shame, Guilt, and Embarrassment Distinct Emotions?" Journal of Personality and Social Psychology 70, no. 6 (1996): 1256-69, doi:10.1037/0022-3514.70.6.1256.

48. Tomkins, Affect Imagery Consciousness.

49. Ibid., 359.

50. Nathanson, Shame and Pride, 19, 144.

51. Gerhart Piers and Milton B. Singer, Shame and Guilt; A Psychoanalytic and a Cultural Study (New York: Norton, 1971): 11.

52. Tomkins, Affect Imagery Consciousness.

53. Nathanson, Shame and Pride, 51.

54. Tomkins, Affect Imagery Consciousness, 359.

55. Thomas J. Scheff, "Depression, Bipolarity and Aggression as Emotion Sequences," J Gen Practice 4, no. 2 (2016): 3, available online at https://www.esciencecentral.org/journals/depressionbipolarity-and-aggression-as-emotion-sequences-2329-9126-1000246.pdf [accessed 8 February 2016].

56. Qun G. Jiao and Anthony J. Onwuegbuzie, "Dimensions of Library Anxiety and Social Interdependence: Implications for Library Services," Library Review 51, no. 2 (2002): 71-78, doi:10.1108/00242530210418837.

57. Onwuegbuzie, Jiao, and Bostick, Library Anxiety, 28-31.

58. Ibid., 28-31.

59. Qun G. Jiao and Anthony J. Onwuegbuzie, "Perfectionism and Library Anxiety among Graduate Students," Journal of Academic Librarianship 24, no. 5 (1998): 365-71.

60. Ronda L. Fee and June P. Tangney, "Procrastination: A Means of Avoiding Shame or Guilt?" Journal of Social Behavior and Personality 15, no. 5 (2000): 167-84.

61. Fee and Tangney, "Procrastination," 167.

62. Qun G. Jiao, Denise A. DaRos-Voseles, Kathleen M.T. Collins, and Anthony J. Onwuegbuzie, "Academic Procrastination and the Performance of Graduate-Level Cooperative Groups in Research Methods Courses," Journal of the Scholarship of Teaching and Learning 11, no 1 (2011): 120, available online at http://files.eric.ed.gov/fulltext/EJ915928.pdf [accessed 8 February 2017].

63. Fee and Tangney, "Procrastination." 
64. Jiao and Onwuegbuzie, "Perfectionism and Library Anxiety."

65. June P. Tangney, "Perfectionism and the Self-Conscious Emotions: Shame, Guilt, Embarrassment, and Pride," in Perfectionism: Theory, Research, and Treatment, eds. Gordon L. Flett and Paul L. Hewitt (Washington, D.C.: American Psychological Association, 2002), 199-215.

66. Paul L. Hewitt, "Validation of a Measure of Perfectionism," Journal of Personality Assessment 53, no 1 (1989): 133-44, doi:10.1207/s15327752jpa5301_14.

67. Fee and Tangney, "Procrastination," 172.

68. Suzanne M. Retzinger, "Identifying Shame and Anger in Discourse," American Behavioral Scientist 38, no. 8 (1995): 1104-1113, doi:10.1177/0002764295038008006.

69. Ibid., 1105.

70. Ibid., 1108.

71. Scheff, "Shame in Self and Society."

72. "LibQUAL+Comments Sorted by Library Branch," University Library, University of Illinois at Urbana-Champaign, available online at https://www.library.illinois.edu/staff/assessment/2008-2/ commentsbranch/ [accessed 7 July 2016].

73. Lewis, Shame and Guilt in Neurosis, 15-16.

74. Ibid., 197.

75. Scott W. Lee, "An Exploratory Case Study of Library Anxiety," 105.

76. Ibid., 105.

77. Retzinger, "Identifying Shame and Anger in Discourse," 1108.

78. Nahyun Kwon, "A Mixed-Methods Investigation of the Relationship between Critical Thinking and Library Anxiety among Undergraduate Students in Their Information Search Process," College \& Research Libraries 69, no. 2 (2008): 117-31, doi:10.5860/crl.69.2.117.

79. Ibid., 124.

80. Retzinger, "Identifying Shame and Anger in Discourse," 1108.

81. Colleen Cook and Fred M. Heath, "Users' Perceptions of Library Service Quality: A LibQUAL+ Qualitative Study," Library Trends 49, no. 4 (2001): 548-84, available online at www. libqual.org/documents/admin/cookheath.pdf [accessed 7 February 2017].

82. Ibid., 555.

83. Ibid., 579.

84. Tomkins, Affect Imagery Consciousness, 353-54.

85. "2014 LibQUAL + Report," Polk Library, University of Wisconsin Oshkosh, available online at www.uwosh.edu/library/about/planning/surveys/2014-libqual-report.pdf [accessed 7 February 2017].

86. Robert G. Lee and Gordon Wheeler, The Voice of Shame (San Francisco: Jossey-Bass Publishers, 1996), 107.

87. Scheff and Retzinger, Emotions and Violence, 60.

88. Lewis, Shame and Guilt in Neurosis, 233.

89. Scheff and Retzinger, Emotions and Violence, 152.

90. "LibQual Comments Sorted by Group," University Library, University of Illinois at UrbanaChampaign (2008), available online at www.library.illinois.edu/libqual/results/commentsgroup. html [accessed 15 May 2016].

91. Scheff and Retzinger, Emotions and Violence.

92. Paul Gilbert, "What is Shame? Some Core Issues and Controversies," Shame: Interpersonal Behaviour, Psychopathology, and Culture (1998): 10; Scheff and Retzinger, Emotions and Violence, $108-12$.

93. Justina O. Osa, "The Difficult Patron Situation: Competency-based Training to Empower Frontline Staff," Reference Librarian 36, no. 75/76 (2002): 265-78, doi:10.1300/J120v36n75_24.

94. Ibid., 272.

95. Ibid., 272.

96. Mary Beth Chappell Lyles, "Neutralizing Conflict: Counseling Techniques for Law Librarians," AALL Spectrum 19, no. 8 (2015): 12-14, available online at www.aallnet.org/mm/Publications/ spectrum/archives/Vol-19/No-8/counseling.pdf [accessed 7 February 2017].

97. Ibid., 13.

98. Nathanson, Shame and Pride, 348.

99. "LibQual 2015 User Comments and Responses," Olin Library, Rollins College, available online at www.rollins.edu/library/about/libqual/libqual2015faq.html\#serviceneg [accessed 14 May 2016].

100. Thomas J. Scheff, "Self-Defense against Verbal Assault: Shame, Anger, and the Social Bond," Family Process 3, no. 3 (1995): 271-86, doi:10.1111/j.1545-5300.1995.00271.x.

101. Ibid., 273.

102. Scheff and Retzinger, Emotions and Violence.

103. Scheff and Retzinger, Emotions and Violence. 
104. Doris Van Kampen-Breit and Rachel Cooke, "Do They Think We're the Frenemy? Examining Student Anxiety and Service Perception in Today's Academic Libraries," Library Leadership \& Management 30, no. 1 (2015), available online at https://journals.tdl.org/llm/index. $\mathrm{php} / 1 \mathrm{~lm} /$ article/view/7117/6352 [accessed 7 February 2017].

105. Kuhlthau, "Inside the Search Process"; Kwon, "A Mixed-Methods Investigation." 